\title{
Study in The Inhibitory Effect of Disinfectants and Antiseptic Traded From Local Market in Nineveh The Province of on Some Pathogenic Bacteria
}

\author{
Bushra D. Hamad \\ Department of Biology , College of Education , University of Mosul \\ bmicro161@gmail.com
}

Received

25/09/2012
Accepted

$5 / 12 / 2012$

\begin{abstract}
This study deals with the comparison of the effect of some disinfectants used in Hospitals from local market of Nineveh province from different origins, on some Gram negative and Gram positive bacteria isolated from burns and wounds. These disinfectants includes : Dettol (septol) ,Hepatine, Povidine-iodine , Hand sterilizer all of them from local, Arabic and international origins.

Results showed a clear resistance of the studied bacteria, and differences in bacterial sensitivity toward disinfectants depends on its origins and bacterial species .It was clear that the disinfectant (hepatine) was the best disinfectant in inhibiting growth, the danish origin was the best of them then Jordanian origin, the second disinfectant (dettol) of which the Jordanian origin was also the best, then (povidineiodine) of which the Emirates origin was the best and then (hand sterilizer gel) of France origin was best.
\end{abstract}

Keyword: Antiseptic, Disinfectants, Hepatine 


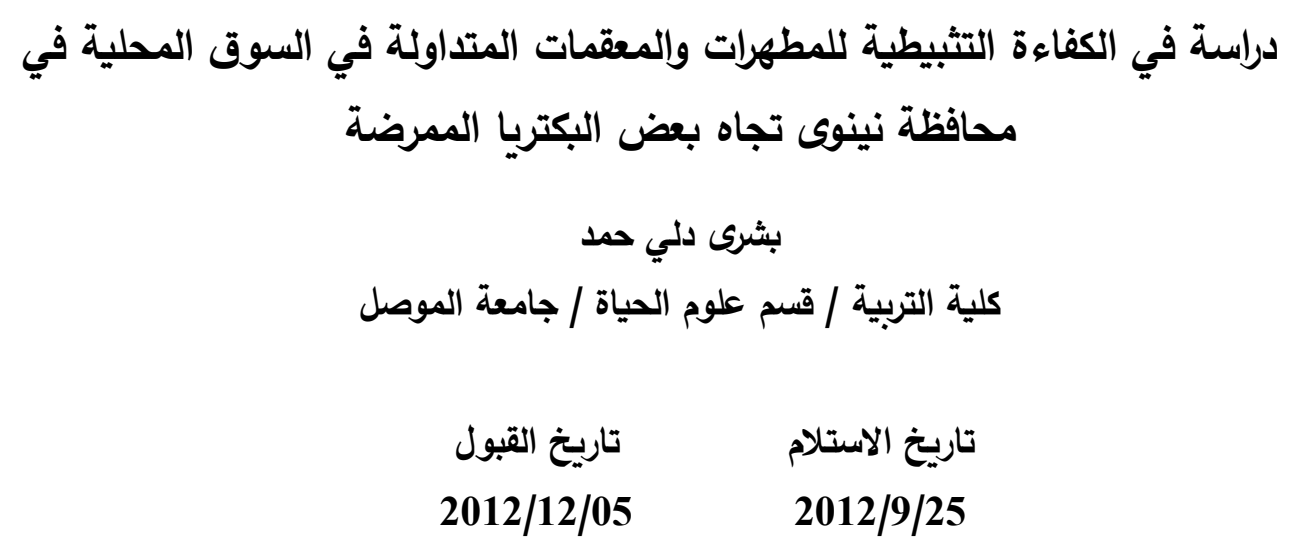

\section{الخلاصة}

اجريت هذه الدراسة لمقارنة كفاءة مجموعه من المطهرات المتداولة في السوق المحلية والمستخدمة في المستشفيات لمحافظة نينوى ومن مناشئها المختلفة على مجموعة من البكتريـا السالبة والموجبة لصبغة كرام

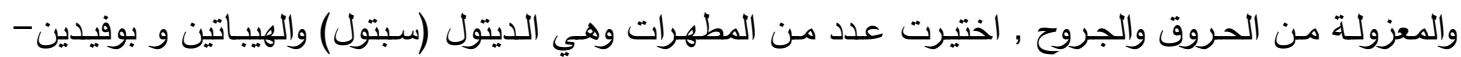
ايودين ومعقم اليدين (جل) من مناشأ محلية وعربيه ودوليه.

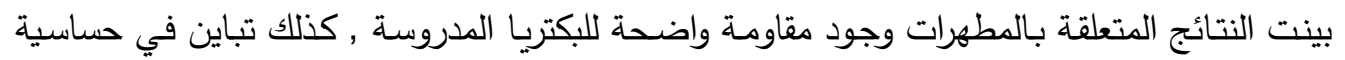
البكتريا للمطهرات اعتمادا على المنشأ ونوع البكتريا , وتبين ان مطهر الهيباتين كان الافضل في التثبيط ومن وافن

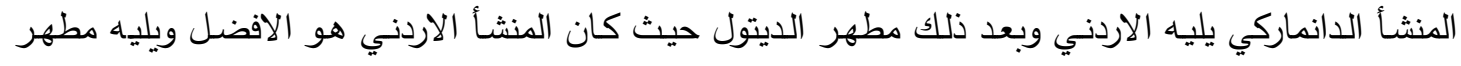

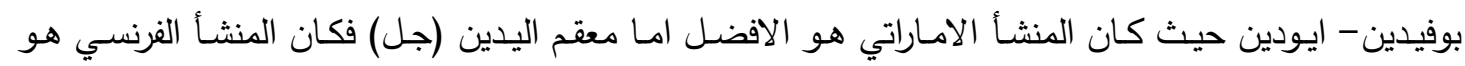
الافضل. الكلمات المفتاحية: المعقمات، المطهرات، الهيباتين 


\section{المقدمة}

تستخدم المعقمات والمطهرات الكيميائية في تعقيم الادوات الجراحية اضافة الى الأسطح المختلفة التي

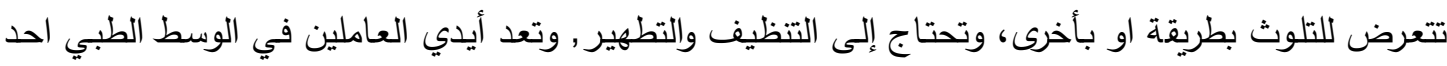

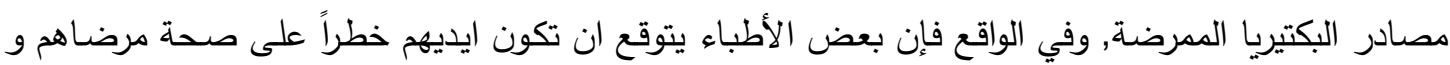
على صحتهم الثخصية][1]. يعد انتثار البكتريا المقاومة للمطهرات مشكلة رئيسية جعلت الشركات المنتجة للمطهرات امام تحديات صعبة لتفاقم هذه المشكلة الخطيرة. ونتيجـة للحاجـة المستمرة الى استخدام المطهرات المختلفة فان الثركات

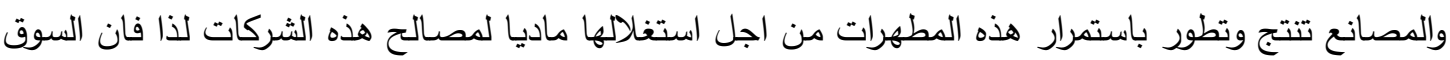

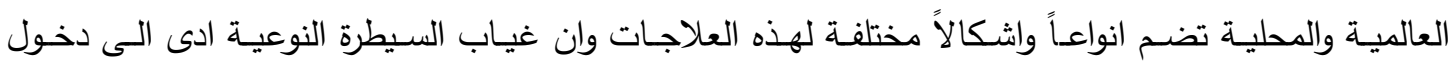
واستهلاك منتجات متدنية الجودة والكفاءة [3,2].

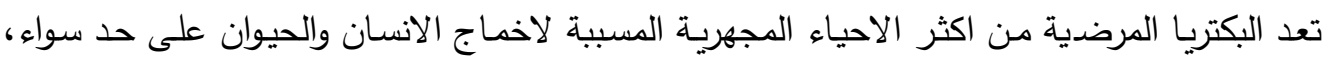
وتعد الـ Staphylococcus aureus من البكتريا الموجودة بشكل طبيعي في الجسم اذ تتواجد في المنخرين او

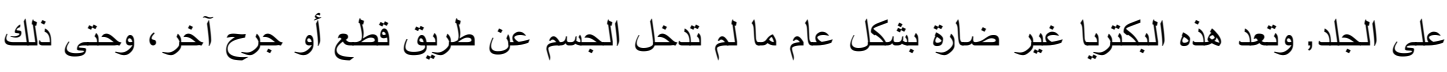

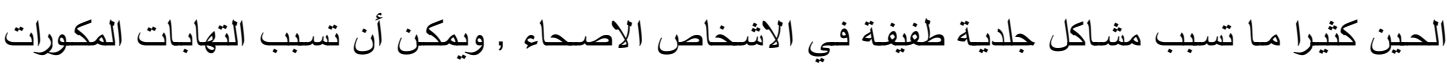
العنقودية العادي مرض خطير , وكذلك تسبب التهابات في أنسجة الجلد والعظام والمفاصل والخراجات وصمامات التهات التهات القلب الطبيعية والتهابات الجروح و ذات الرئة أو التهاب السحايا ومدكن ان تتطور وتسبب إنتان الدم وهذات

يزدهر في محيط المستثفى [5,4].

وتعد بكتريا Pseudomonas aeruginosa من البكتريا المسببة للعديد من الاخماج , ويتميز هذ البـائ

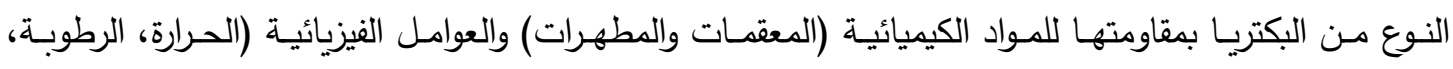

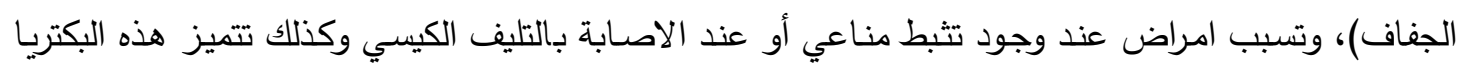

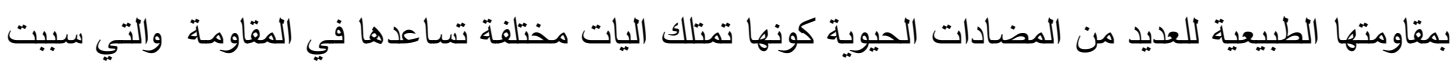
فثل المضادات الحيوية في القضاء على الاصـابة المتسببة عن هذا النوع البكتيري مما دعا المختصين للبحث تهن

عن مصادر جديدة للمضادات الميكروبية تستعمل بوصفها بدائل عن المضادات التقليدية [7,6]. اجري هذا البحث بهدف دراسة كفاءة المطهرات المختلفة المناشأ المتداولة في السوق المحلية في مدينة الموصل ومستشفياتها ومدى فعاليتها في الاستخدام تجاه البكتريا المختلفة.

\section{المواد وطرائق العمل}

\section{1-البكتريا المدروسة}

استخدمت في هذه الدراسـة عدد من البكتريـا الموجبة والسالبة لصبغة كرام والمعزولـة في قسم علوم

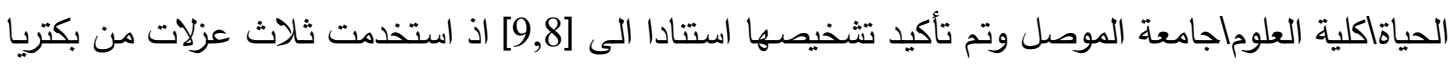
Staphylococcus aureus

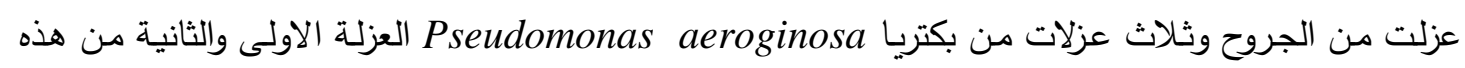
البكتريا عزلت من الحروق اما العزله الثالثه عزلت من منتلات الجروح. 
2-المطهرات

استخدمت المطهرات ذات المناشأ المختلفة وذلك لاختبار فعاليتها التثبيطية تجاه البكتريا المستخدمة قيد

$$
\text { الدراسة وهي موضحة في الجدول (1) }
$$

الجدول(1) انواع المطهرات المستخدمة في الدراسة والمناشأ المصنعة لها.

\begin{tabular}{|c|c|c|c|c|}
\hline البلد المصنع لها & 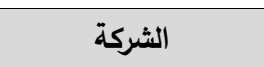 & التركيز & اسم المطهر & $ت$ \\
\hline \multicolumn{5}{|c|}{ سبتول } \\
\hline سوريا - س & حلب & - & لينول & 1 \\
\hline عمان-الاردن & سبارتين & - & ل ل ل ل ل ل & 2 \\
\hline 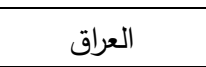 & 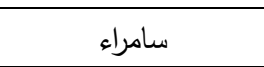 & $\% 2$ & سبتول & 3 \\
\hline السعودية & مام & - & ديتول & 4 \\
\hline العراق & 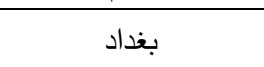 & $\% 2$ & ديتول & 5 \\
\hline \multicolumn{5}{|c|}{ هيباتين } \\
\hline العراق & 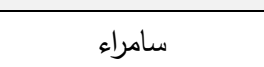 & $\% 5-4$ & Hexatane & 6 \\
\hline دانمارك & WHO & $\% 1.5$ & Cetrimide & 7 \\
\hline سوريا & حلب & $\% 4$ & هيباتين & 8 \\
\hline الاردن & 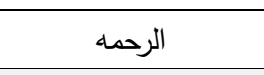 & $\% 4$ & Hexatane & 9 \\
\hline \multicolumn{5}{|c|}{ بوفيدين -أيودين } \\
\hline العراق & شركة الثرق الاوسط & $\% 10$ & ل مبوفيدين - أيودين & 10 \\
\hline تركيا & اسطنبول & $\% 70$ & بوفيدين - أيودين & 11 \\
\hline إمارات & Ecolab & - & Skinman soft & 12 \\
\hline سوريا & حلب & $\% 4$ & بوفيدين- أيودين & 13 \\
\hline الاردن & 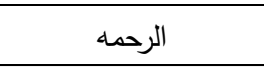 & - & بوفيدين - أيودين & 14 \\
\hline \multicolumn{5}{|c|}{ معقم اليدين (جل) } \\
\hline فرنسي & Biofresh & - & Biofresh & 15 \\
\hline صيني & Cleanser & - & Hand sanitizer & 16 \\
\hline تركيا & Turkuaz medical & - & Germ of lemon & 17 \\
\hline مصري & SAR & - & Carfarma & 18 \\
\hline
\end{tabular}

طرائق العمل

\section{اختبار الفعالية التثبيطيه للمطهرات مختبريا}

اختبرت الفعالية التثبيطية للمطهرات (طريقة الانتشار بالأقراص) باستخدام طريقة اختبار الحساسية

على نمو البكتريـا قيد الدراسـة وبالاعتمـاد على طريقة Bauer وجماعته سنة 1966[10] حيث حضر المعلق البكتيري في وسط المرق المغذي وبتركيز 108/ خلية/ سم3 وذلك مقارنـة هـع انبوب ماكفرلاند القياسي رقم (0.5) , ونقل 0.1 سم3 من المعلق البكتيري ولقح باستخدام ماسحة قطنية معقدة بعد ذلك وضعت اقراص من ورق الترشيح (Whatman N0.1) بقطر 6ملم مشبعة بتراكيز المطهرات المحضرة ثم ثبتت الاقراص بواسطة 
ملقط معقم على سطح الاطباق الملقحة وحضنت بدرجة حرارة 37م ولمدة 24 ساعة وبعدها تم قياس اقطار

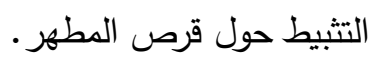

\section{النتائج والمناقشة}

يوضـح الجدول (2) اختلاف تأثير المطهرات والمعقدات باختلاف المناشأ المصنعة واختلاف تركيزها على البكتريـا الموجبة والسـالبة لصبغة كرام قيد الدراسـة حيث تباينت اقطـار التثبـيط بـاختلاف نـوع البكتريـا, والتراكيز , والثركة المصنعة فقد اظهر النتائج تأثير ديتول (سبتول Septol) اذ يلاحظ ان الديتول من معظم المناشأ المستخدمة كانت ذات قدرة تثبيطيه على البكتريا قيد الدراسة واختلف هذا التأثير باختلاف النوع البكتيري اذ وجد ان ديتول سامراء اعطى قدرة تثبيطيه على عزلتين وكانت اعلى قدرة تثبيطيه للعزلة الثانية من . staph.

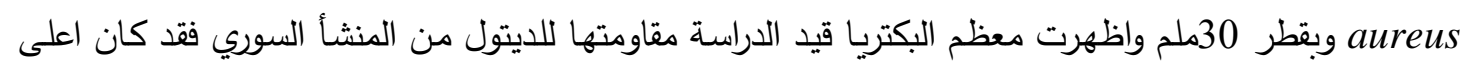

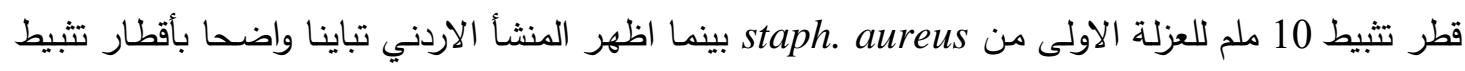

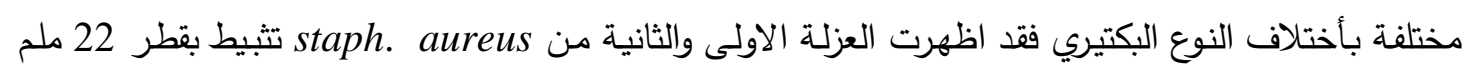

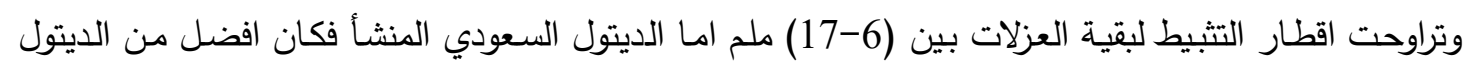
الاردني المنشأ في قدرته التثبيطيه واعطى اعلى قدرة تثبيط للعزلة الاولى staph. aureus بقطر 24 ملم وقد يعود اختلاف هذا التأثير الى انه ذو مستوى تطهير واطئ على P. aerogenosa شكل(1) [13:

جدول (2) تأثير المطهرات باختلاف مناشئها على البكتريا قيد الدراسة بأقطار تتبيط بالملم.

\begin{tabular}{|c|c|c|c|c|c|c|c|c|c|c|c|c|c|c|c|c|c|c|c|}
\hline \multicolumn{4}{|c|}{ معقم اليدين (جل) } & \multicolumn{5}{|c|}{ بوفيدين -أيودين } & \multicolumn{4}{|c|}{ هيباتين } & \multicolumn{5}{|c|}{ ديتول } & \multirow[t]{2}{*}{ المطهرات } & \multirow{2}{*}{ رقلم } \\
\hline $\begin{array}{l}\xi \\
\text { y): }\end{array}$ & $\bar{y}^{3}$ & $f:$ & 争 & $\bar{\jmath}$ & के & $\frac{\overline{3}}{\bar{n} \bar{b}}$ & $\bar{y}^{3}$ & $\frac{y}{19}$ & $\bar{\jmath}$ & के & $\frac{\frac{7}{3}}{\sqrt[3]{3}}$ & $\frac{y}{\sqrt{-9}}$ & $\frac{7}{7}$ & $\begin{array}{l}3 \\
3 \\
\text { 3.: }\end{array}$ & $\frac{3}{\frac{3}{a}}$ & $\overline{\hat{\eta}}$ & के & & \\
\hline 10 & 6 & 25 & 30 & 8 & 6 & 12 & 17 & 9 & 14 & 10 & 38 & 30 & 12 & 24 & 10 & 22 & 10 & Staph.aureus & 1 \\
\hline 6 & 6 & 6 & 6 & 37 & 6 & 30 & 17 & 6 & 34 & 6 & 27 & 21 & 15 & 10 & 30 & 22 & 6 & Staph.aureus & 2 \\
\hline 9 & 9 & 6 & 6 & 27 & 6 & 6 & 6 & 6 & 22 & 6 & 31 & 17 & 13 & 16 & 20 & 14 & 8 & Staph.aureus & 3 \\
\hline 10 & 6 & 6 & 6 & 6 & 6 & 20 & 15 & 10 & 17 & 6 & 20 & 20 & 17 & 20 & 9 & 17 & 6 & p.aeruginosa & 1 \\
\hline 6 & 6 & 6 & 6 & 8 & 6 & 6 & 7 & 6 & 10 & 6 & 9 & 6 & 15 & 6 & 6 & 6 & 6 & p.aeruginosa & 2 \\
\hline 6 & 6 & 6 & 6 & 13 & 6 & 6 & 9 & 6 & 11 & 6 & 10 & 6 & 14 & 6 & 6 & 6 & 6 & p.aeruginosa & 3 \\
\hline
\end{tabular}




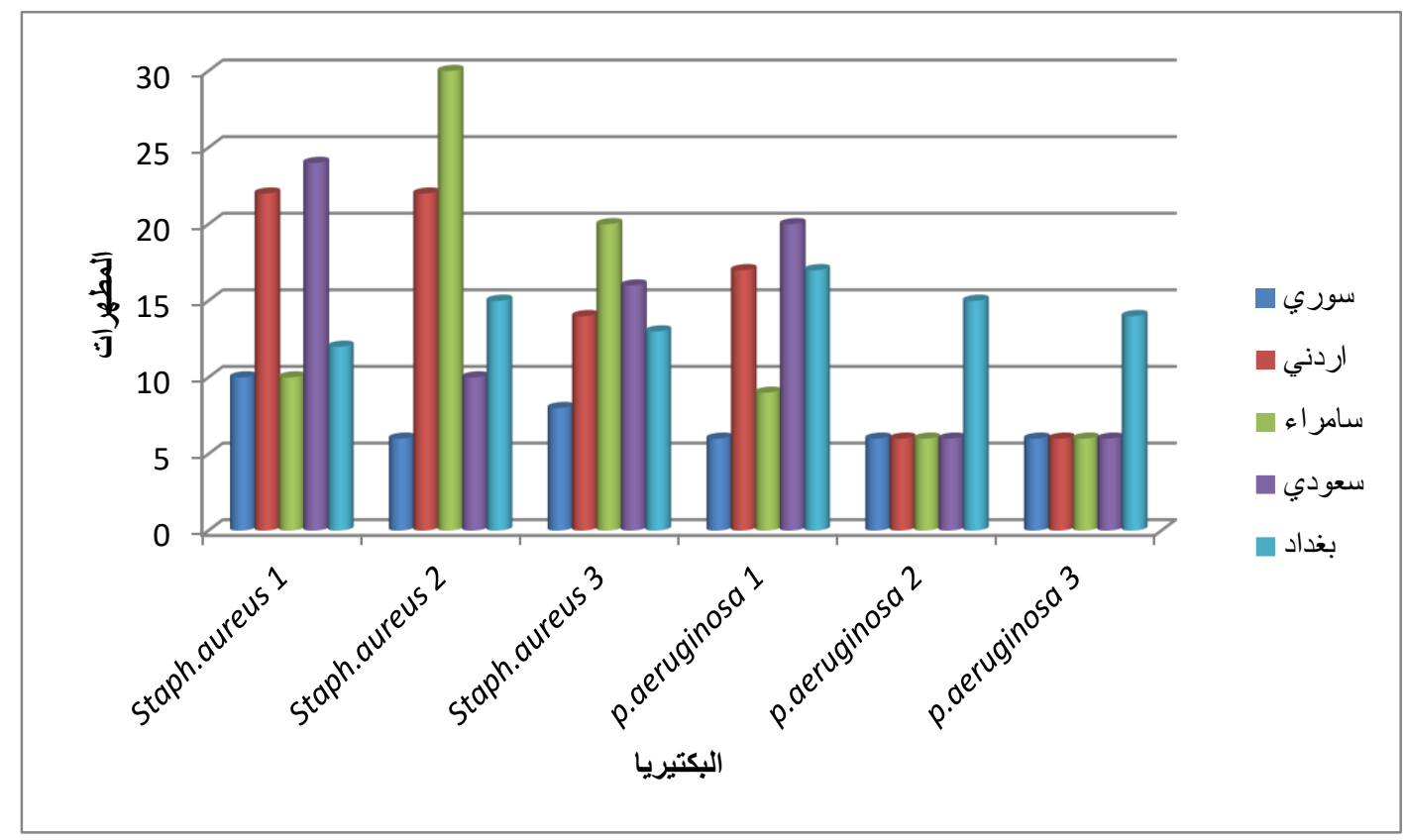

شكل (1) تأثير الديتول باختلاف مناشئه على البكتريا قيد الدراسة أقطار تتبيط بالملم

وبالعودة للجدول (2) يتضح تباين تأثير مطهر الهيباتين (الكلورهكدين) على العزلات الموجبة لصبغة

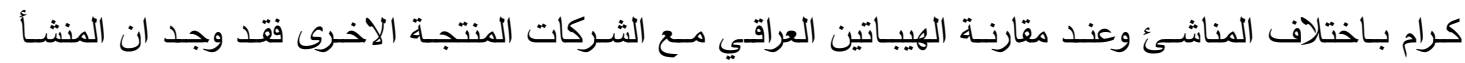

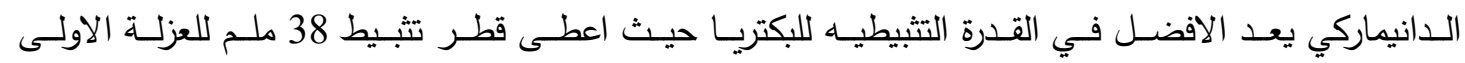

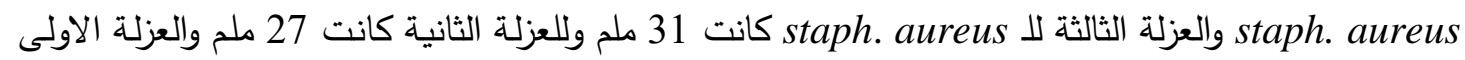

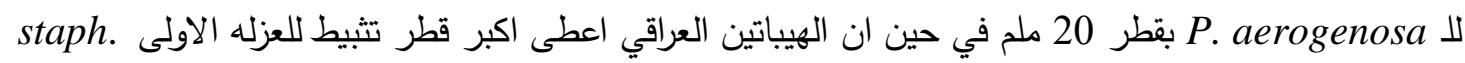
30 aureus وتراوحت اقطار التثبيط لبقية العزلات بين (11-22) ملم في ان حين الهيباتين السوري كان الاقل تأثيرا مقارنة بالمناشئ الاخرى حيث اعطى اكبر قطر تثبيط للعزلة الاولى staph. aureus بقطر 10 ملم وقد اختلف تأثير

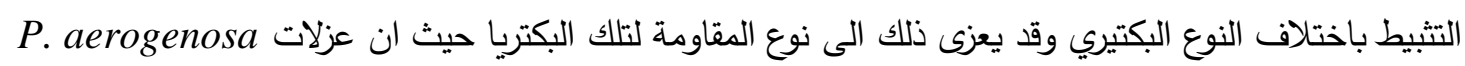
كانت اقل تأثرا من عزلات staph. aureus اذ ان البكتريـا السالبة لصبغة كرام تكون اقل حساسية للمطهرات (الكلورهكسين) والذي يعود الى الطبقات الخارجية للجدار الخلوي والتغييرات في نفاذية الغشاء البلازمي للبكتريا شكل (2) [14,13,12 


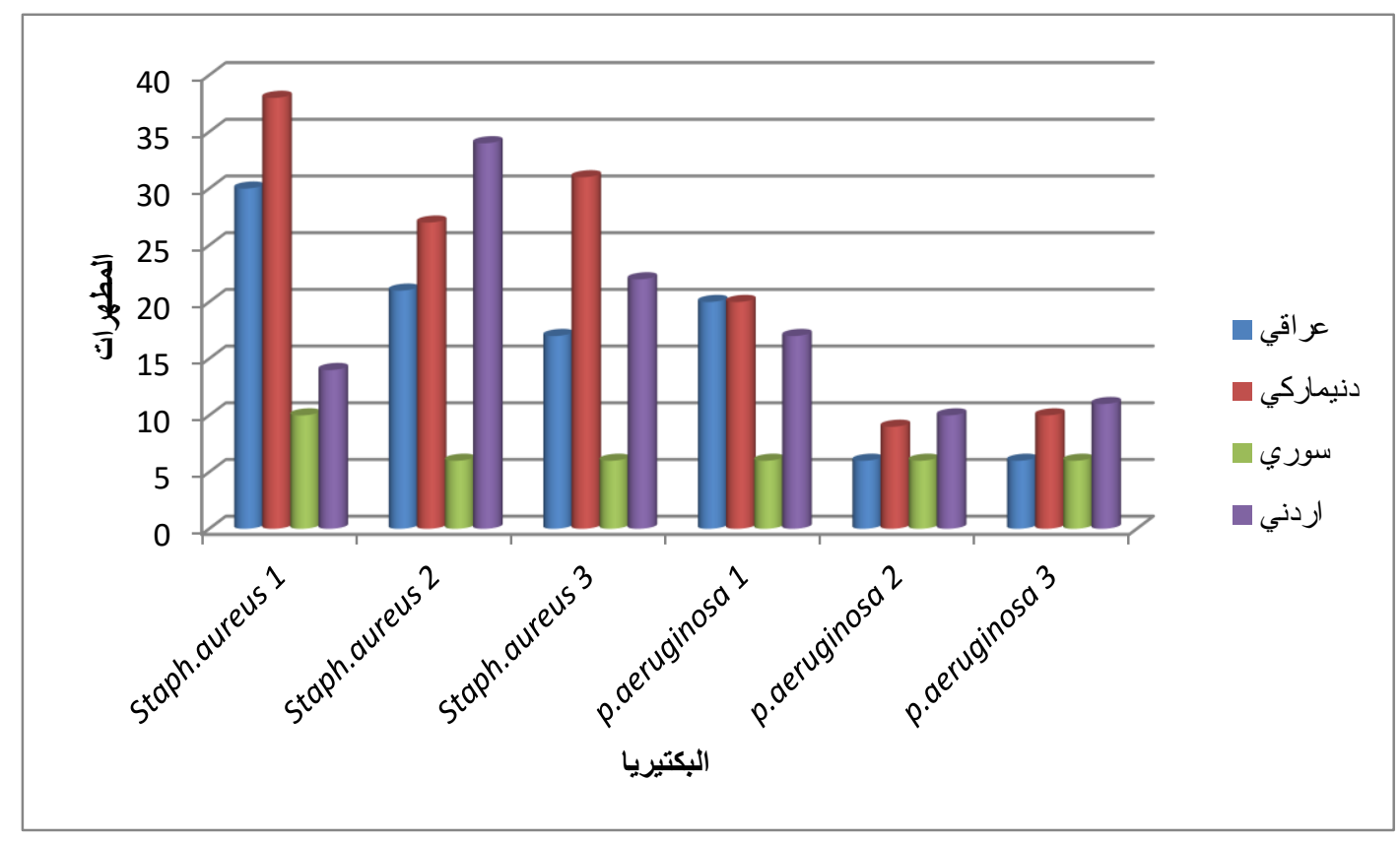

شكل (2) تأثير الهيباتين باختلاف مناشئه على البكتريا قيد الدراسة أقطار تثبيط بالملم

ويتضح من الجدول (2) ايضا ان مطهر بوفدين ايودين كان تأثيره متباين باختلاف المناشأ حيث ان

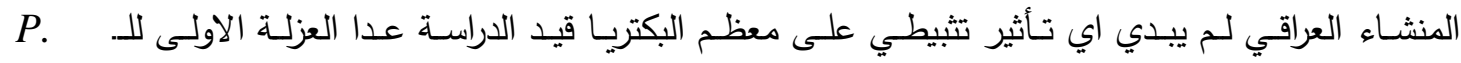
aerogenosa اعطى المنشأ الاردني اعلى قدرة تثبيطية وبقطر 37 ملم للعزلة الثانية staph. aureus وتراوحت الاقطار لبقية

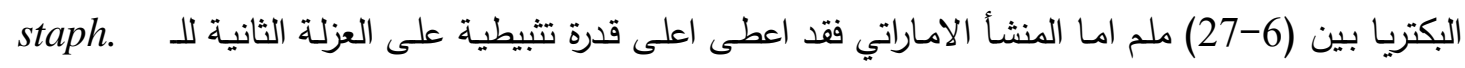
aureus

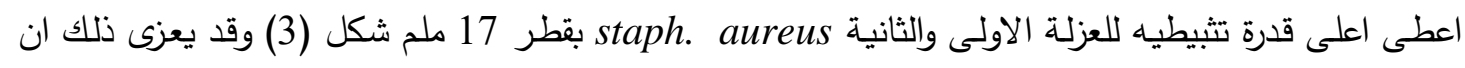

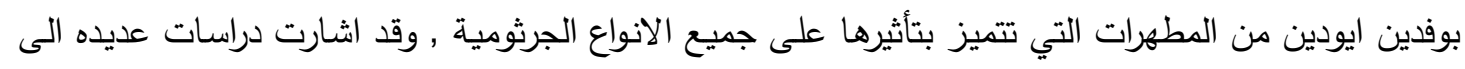

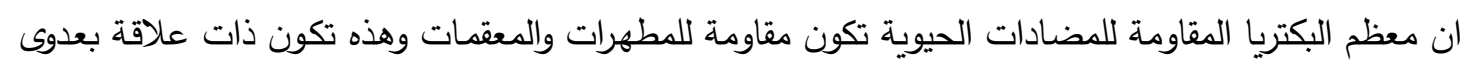

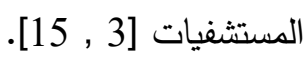




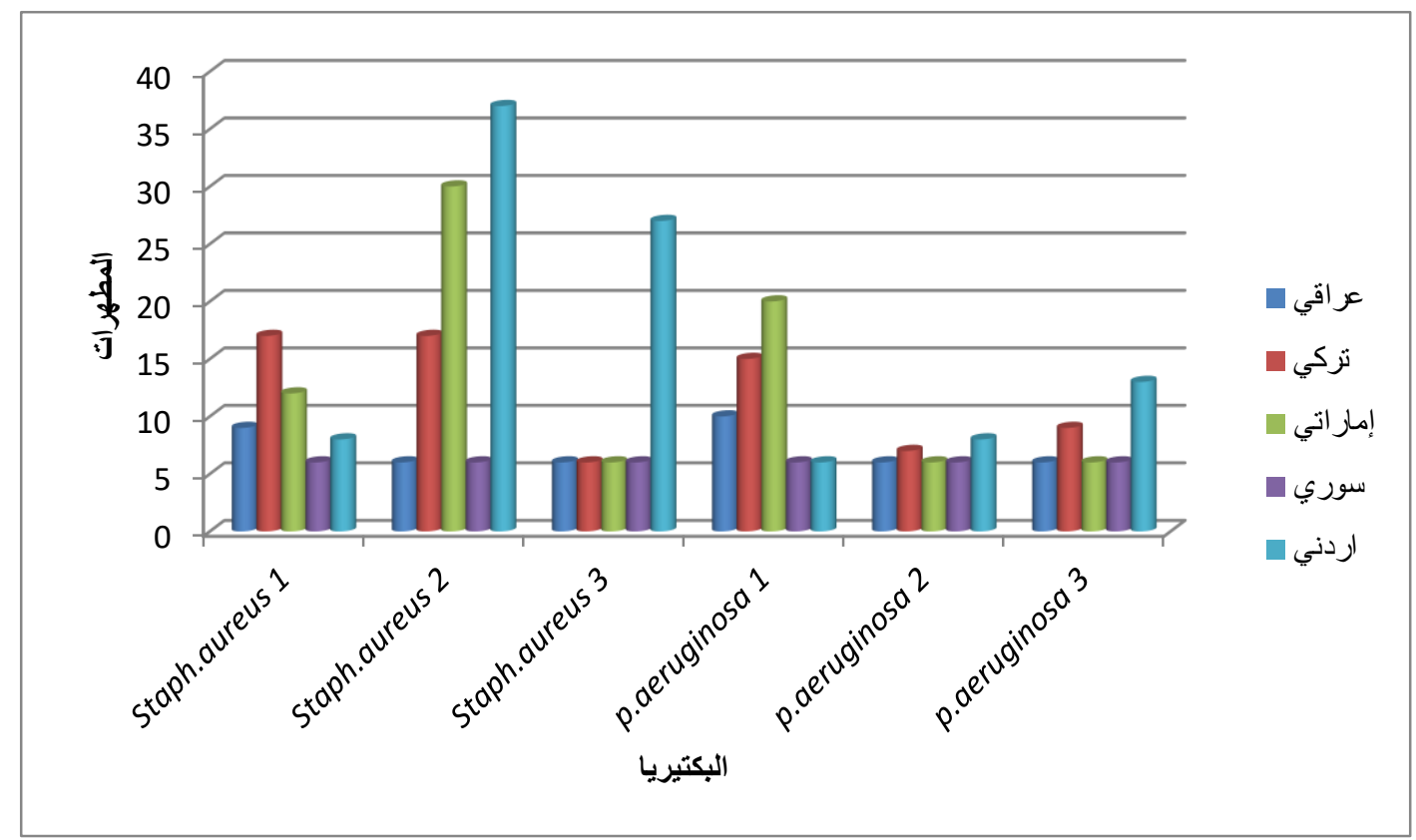

شكل (3) تأثير بوفيدين-أيودين باختلاف مناشئه على البكتريا قيد الدراسة أقطار تثبيط بالملم

كما اظهر الجدول (2) تأثير معقم اليدين جل تركي المنشأ قليل او معدوم التأثير على جميع العزلات

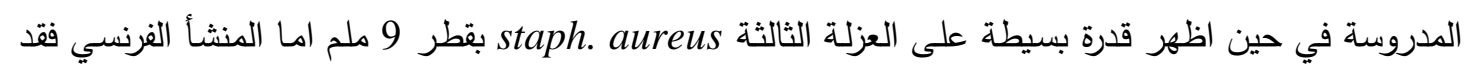
staph. aureus تباينت قدرته التثبيطه على العزلات الددروسة فقد اعطى اعلى قدرة تثبيط للعزلة الاولى فئه بقطر 30 ملم

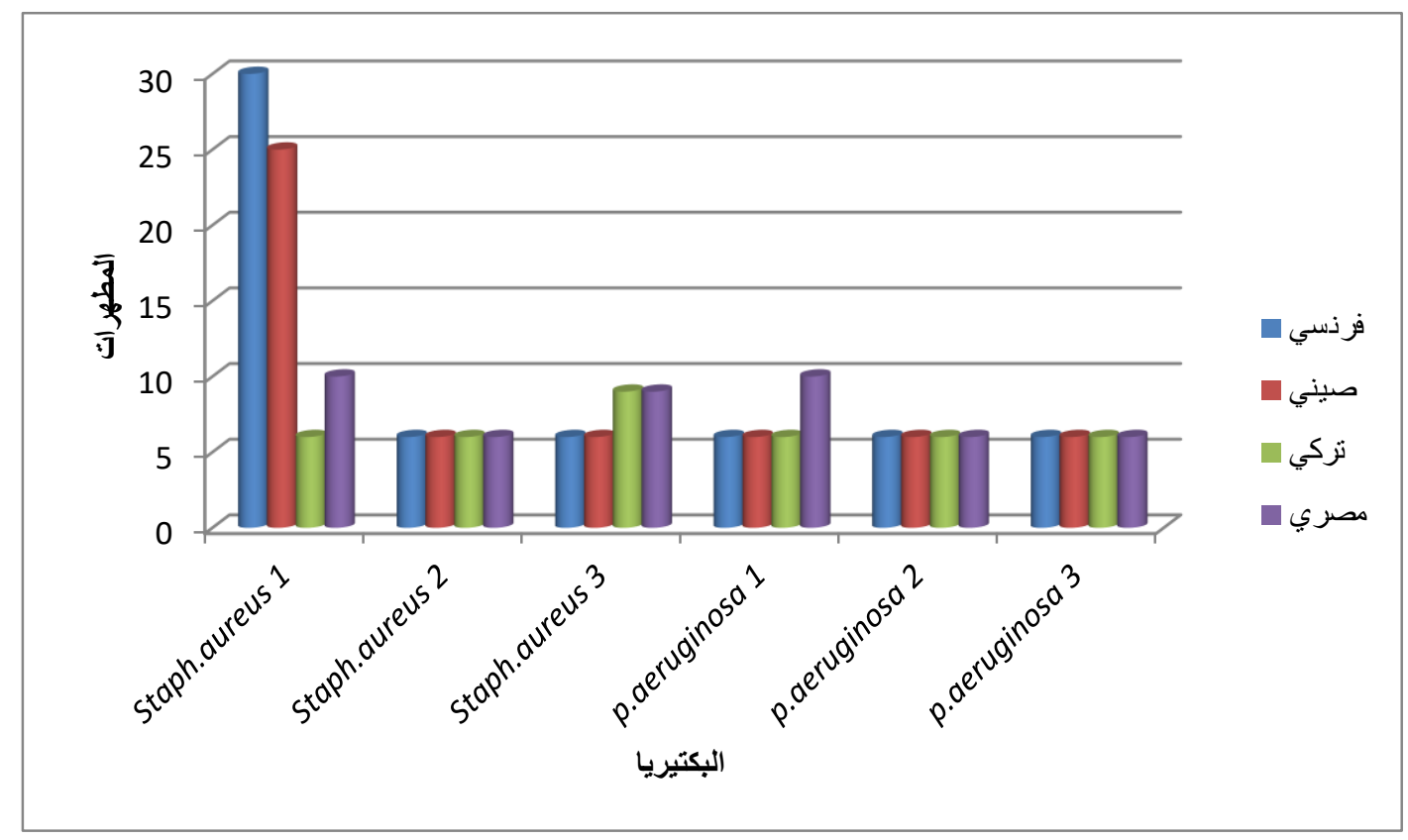

شكل (4) تأثير معقم اليدين (جل) باختلاف منشائه على البكتريا قيد الدراسة أقطار تثبيط بالملم 
في حين كان المنشأ المصري قليل التأثير حيث اعطى اعلى قدرة تثبيطيه بقطر 10 ملم لكل من العزلة الاولى للا Staph. aureus ولا P. aerogenosa , واعطى معقم اليدين جيل الصيني المنشأ اعلى قدرة تثبيطيه بقطر 25 ملم للعزلة الاولى staph. aureus, وقد يعود اختلاف هذا التأثير الى نسبة تركيز Ethyl alcohol

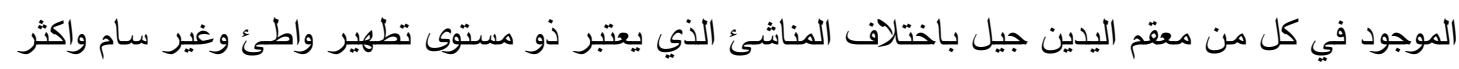

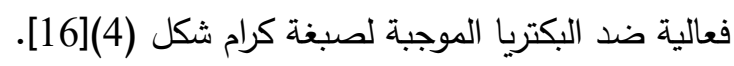

اما بالنسبة لافضل مطهر للبكتريا قيد الدراسة فقد كان هيباتين والديتول حيث اعطى مطهر الهيباتين

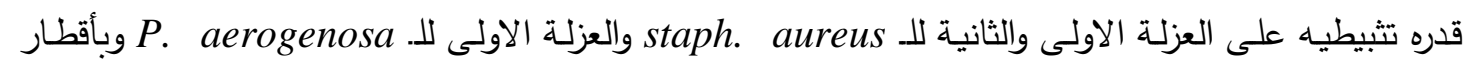

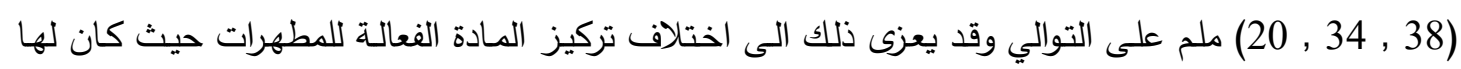

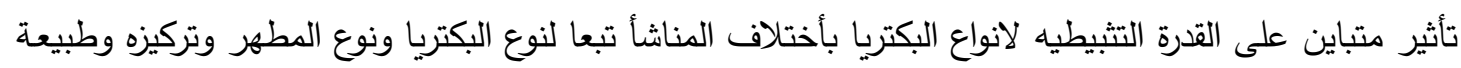

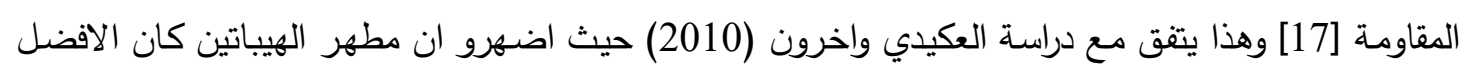

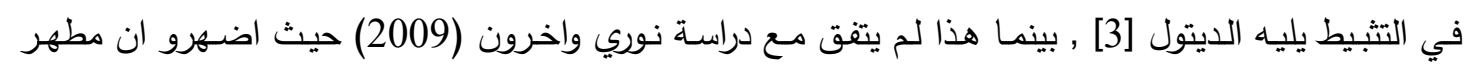

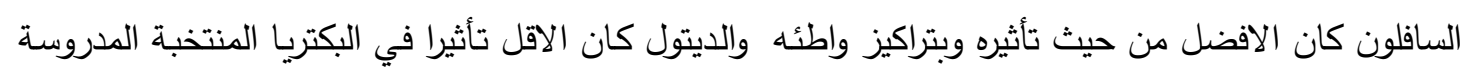

\author{
شكر وعرفان \\ اتقدم بالثكر الجزيل لجامعة الموصل / كلية التربية للعلوم الصرفة.
}

1-Dupuy, M. ; Mazoua, S. ; Berne, F. and Bodet, C. Journal ISSN., 45: (3) 10871094, (2011).

2-Brook ,G.F. ; Carroll , K. C. ; Butel ,J. S. and Morse , S. A., "Jawetz, Melnick and Adelbergs Medical Microbiology" 24th ed., McGraw-Hill Companies Inc. USA (2007).

3- Essa, M.A; Alwan, A.J. and Al-Kayat, E.M. M.Sc. Thesis, College of Science, University of Mosul (2010). (In Arabic).

4-Manal, M. B., Saudi pharmaceutical journal., 16: ( 2) 165-170, (2008).

Al-Nashet, A.A. M.Sc. Thesis, College Science, University of Abdul Aziz, KSA (2011). (In Arabic).

6- Fraimow, H.S. and Abrutyn, E., Dis. Clin. North. Am., 9 : 497-530, (1995).

7-Massi, L. ; Guittard, F. ; Levy, R. and Geribaldi, S., Journal: European Journal of Medicinal Chemistry ISSN. 44 (4) 1615-1622, (2009).

8- Presccott, L.M; Harely, T.P. and Klein, D.A. "Microbiology" 4th ed. McGraw- Hill companies, Inc, USA (2002).

9- 15. Benson, H.J. "Microbiological. Application". 8th ed. McGraw-Hill Companiesm Inc., USA (2002).

10- Bauer, A., Kirby, W.A., Sherris, J.S., and Turk, M., Am. J. Clin. Pathol., 45493496, (1966). 
11-Mclaughlin, A. J. and Palermo, R. "Infection control in respiratory care". 2nd . ed. Aspen Publ. Inc., Maryland (1966).

12-Noparat, W.; Siripanichakorn, K.; Tribudharat, C. and Danchaivijitr, S., J Med Assoc Thai., 88 (Suppl 10): 177-182, (2005).

13-Kampt, G.; Hofer, M. and Wendt, C., J. Hosp. Infect. 24:143-150, (1999).

14-Fraise, A. P. M., J. Hosp. Infect.43:255-264, (1999).

15-Rutala , W. A. ; Aguiar, N. C. ; Sobsey, M. D. and Weber, D. j., Infect. Coont. Hosp. Epidemiol., 21(1):33-38, (2000).

16- Presccott, L.M; Harely, T.P. and Klein, D.A. "Microbiology" 4th ed. McGrawHill companies, Inc, USA (2002).

17- Willey, J. M.; Sherwood, L. M. and Woolverton, C. J. "Prescott, Harly and Klein,s Microbiology". 7th ed., McGraw Hill Companies Inc. New York (2008).

18- Nori, H.S.; Dawod, I.T. and Mahmod, M.T., M.Sc. Thesis, College of Nursing, University of Mosul (2009). (In Arabic). 